\title{
Durability of concretes prepared with crystalline admixtures
}

\author{
Kosmas K. Sideris*, A. Chatzopoulos, Ch. Tassos, P. Manita. \\ Democritus University of Thrace, Department of Civil Engineers, Building B', University Campus of Xanthi, Kimmeria, Greece
}

\begin{abstract}
The objective of this work was to study the influence of crystalline admixtures on the durability of concrete. Four concrete mixtures - two reference concretes and two alternative mixtures-were produced during the first phase of the research. Influence of curing on the activation of the crystals was investigated on concrete slab specimens. The properties measured were the compressive strength and different durability indicators. The results revealed that crystalline admixtures enhanced the strength and the durability of the alternative mixtures.
\end{abstract}

\section{INTRODUCTION}

Concrete is the most commonly used construction material worldwide and the material with the second greatest consumption globally, just after water. One can say that it is concrete that has been used for the major infrastructures built during the last century all over the world and therefore is the material strongly connected with the development of our society and the improvement of our way of living. However concrete structures do not last forever; deleterious substances penetrate from the surrounding environment into concrete and react with its components resulting in its deterioration and/or corrosion of the embedded steel. In almost all cases, the reactants responsible for concrete deterioration penetrate into the concrete matrix with water. Since durability of concrete is of major concern, both for financial as well as for sustainability issues, reducing or even better minimizing the penetration of water should be of major priority. Water can enter concrete though the network of pores and capillaries that forms during cement hydration, or through cracks and other voids in the concrete. Therefore, almost all concrete structures require protection from water.

It is well known that a carefully designed concrete mixture which is properly produced and executed (transferred on site, cast, vibrated and cured) using a low $\mathrm{w} / \mathrm{cm}$ ratio will result in a final product with low permeability and enhanced durability. However, no concrete is absolutely waterproof [2]. Concrete is a porous material and water can penetrate into its mass through pores and microcracks (formed initially or during the service life of the structure) due to capillary absorption, or due to hydrostatic pressure. Capillary absorption is the movement of water through the small pores in concrete in the absence of an externally applied hydraulic pressure. This is the result of surface tension between the water and the pore walls [3]. Permeability of concrete is the movement of water due to a pressure gradient, such as water in contact with a concrete structure installed underground [3]. A well-known and widely accepted method for reducing the permeability of concrete mixtures and therefore increase their durability is the addition of supplementary cementing materials (SCMs) into concrete mixtures [4,5]. As stated in ACI212.3R-16, a class of materials referred to as permeability-reducing admixtures (PRAs) have been developed to improve concrete durability through controlling water and moisture movement [6] as well as by reducing chloride ion ingress [7-8] and permeability [4]. According to ACI212.3R-16 [3], admixtures intended to reduce water ingress split into two subcategories: PRAs for concrete exposed to nonhydrostatic conditions (PRAN) and PRAs for concrete exposed to hydrostatic conditions (PRAH) [3].

\section{EXPERIMENTAL PROGRAM}

The research was divided into two phases. During the first phase of this research, four concrete mixtures were produced [7] - two conventional and two alternatives with added crystalline admixtures. The concrete mixtures were of $\mathrm{C} 25 / 30$ and $\mathrm{C} 30 / 37$ strength class, according to EN206-1. CEM I 42.5R and CEM II 32.5 (B-M) $\mathrm{N}$ cements were used to produce the mixtures. Aggregates were of limestone origin with a maximum grain diameter of $31.5 \mathrm{~mm}$. Appropriate doses of retarder and polycarboxylate superplasticizer were used to achieve the desired workability and setting time.

The mixing ratio as well as the properties of the fresh concrete mixtures are shown in Table 2. The C30/37 PRAH mixture was produced with CEM II $32.5 \mathrm{~N}$ cement instead of CEMI $42.5 \mathrm{R}$ in order to reduce the production cost of the alternative mixture.

Cubic specimens of $150 \times 150 \times 150 \mathrm{~mm}$ and cylindrical specimens of $100 \times 200 \mathrm{~mm}$ were prepared. All samples were maintained in a curing chamber $\left(\mathrm{T}=20^{\circ} \mathrm{C}\right.$, RH $>98 \%$ ) until the test age. Cylindrical specimens with dimensions of $60 \times 100 \mathrm{~mm}$ were also used for measuring the carbonation depth. 
The $150 \mathrm{~mm}$ cubes were used to measure the compressive strength at the ages of 2 and 28 days as well as to determine the water absorption. Resistance to chloride penetration of concrete was measured in cylindrical specimens with a diameter of $100 \mathrm{~mm}$ and a height of $50 \mathrm{~mm}$ cut off from the $100 \times 200 \mathrm{~mm}$ specimens. These specimens were maintained as above until the age of 28 days. The chloride diffusion coefficient Dnssm was then evaluated according to the procedure described in NT Building 492.

Table 1. Mixing ratio of concrete mixtures.

\begin{tabular}{|c|c|c|c|c|}
\hline $\mathrm{kg} / \mathrm{m} 3$ & $\begin{array}{c}\mathrm{C} \\
25 / 30\end{array}$ & $\begin{array}{c}\mathrm{C} \\
25 / 30- \\
\text { PRAH }\end{array}$ & $\begin{array}{c}\mathrm{C} \\
30 / 37\end{array}$ & $\begin{array}{c}\mathrm{C} \\
30 / 37- \\
\text { PRAH }\end{array}$ \\
\hline CEM I 42,5R & 0 & 0 & 330 & 0 \\
\hline $\begin{array}{c}\text { CEM II/(B-M) } \\
32.5 \mathrm{~N}\end{array}$ & 400 & 320 & 0 & 350 \\
\hline Sand & 1042 & 1105 & 1133 & 1133 \\
\hline Gravel & 180 & 190 & 195 & 195 \\
\hline Coarse & 575 & 610 & 625 & 625 \\
\hline Water & 200 & 160 & 165 & 160 \\
\hline superplasticizer & 1.40 & 1.12 & 1.16 & 1.16 \\
\hline retarder & 5.60 & 4.80 & 5 & 3.5 \\
\hline PRAH & -- & 2.56 & -- & 2.8 \\
\hline W/C & 0.50 & 0.50 & 0.50 & 0.46 \\
\hline S0 (cm) & 25 & 23 & 24 & 21 \\
\hline S30 (cm) & 20 & 22 & 22 & 19 \\
\hline
\end{tabular}

Carbonation resistance was measured in cylindrical specimens $60 \times 100 \mathrm{~mm}$. These specimens were maintained in the above-mentioned wet chamber for 3 days and then remained in a laboratory environment until the age of 28 days. After this age they were inserted into the accelerated carbonation chamber $(\mathrm{RH}=55-60 \%, \mathrm{~T}=$ $20^{\circ} \mathrm{C}, \mathrm{CO} 2=1 \%$ ) where they remained for 60 days.

During the second phase of this research we wanted to examine the effect of curing on activating the crystals. For this reason we produced five concrete slabs $(5.0 \times 5.0 \times 0.15 \mathrm{~m})$ (Figure 1). The reference concrete used was a $\mathrm{C} 20 / 25$ strength class concrete according to EN206-1. CEM II 32.5 (B-M) N cement was used. Aggregates were of limestone origin with a maximum grain diameter of $31.5 \mathrm{~mm}$. This concrete was used for casting of two slabs. The remaining three slabs were cast using the same concrete with the addition of crystalline admixtures $(\mathrm{P}-\mathrm{c} 20 / 25)$ at a percentage of $0.8 \%$ per weight of cement. The mix design characteristics of both concretes are presented in Table 2 .

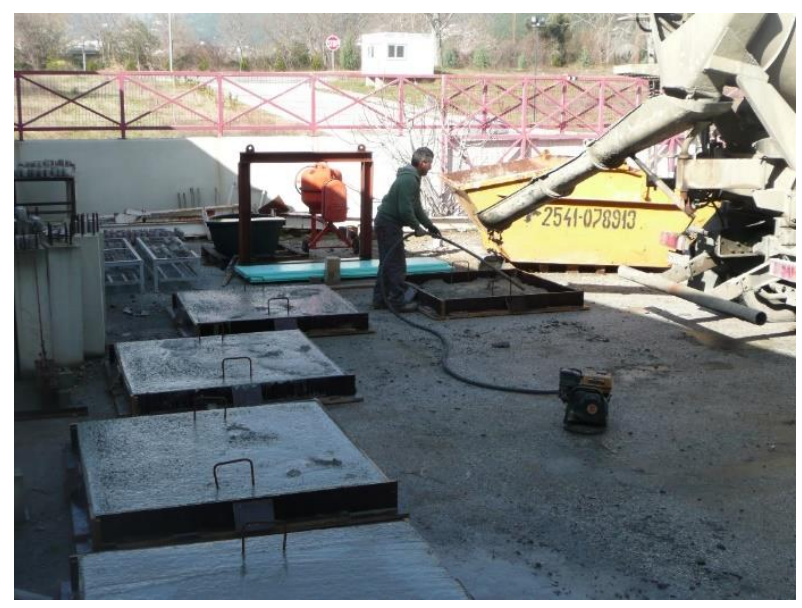

Fig. 1. Concrete slab specimens produced

Table 2. Mixing ratio of $\mathrm{C} 20 / 25$ concrete mixtures.

\begin{tabular}{|c|c|c|}
\hline $\mathrm{kg} / \mathrm{m} 3$ & $\begin{array}{c}\text { Reference- } \\
\text { R-C 20/25 }\end{array}$ & $\begin{array}{c}\text { PRAH } \\
\text { C20/25 } \\
\text { P-C 20/25 }\end{array}$ \\
\hline $\begin{array}{c}\text { CEM II/(B-M) } \\
32.5 \mathrm{~N}\end{array}$ & 280 & 280 \\
\hline Sand & 1150 & 1150 \\
\hline Gravel & 180 & 180 \\
\hline Coarse & 655 & 655 \\
\hline Water & 180 & 180 \\
\hline superplasticizer & 1.10 & 1.10 \\
\hline retarder & 0.56 & 0.56 \\
\hline PRAH & -- & 2.24 \\
\hline W/C & 0.64 & 0.64 \\
\hline S0 (cm) & 19 & 19 \\
\hline S30 (cm) & 15 & 16 \\
\hline
\end{tabular}

Cubic specimens of $150 \mathrm{X} 150 \mathrm{X} 150 \mathrm{~mm}$ were prepared and used for measuring the compressive strength at different ages. All samples were maintained in a curing chamber $\left(\mathrm{T}=20^{\circ} \mathrm{C}, \mathrm{RH}>98 \%\right)$ until the test age.

After casting, the concrete slabs were cured using different curing scenarios. Slabs 1 and 2- cast with reference concrete- were cured under wet burlap for one and seven days respectively. Slab 3-cast with the concrete containing crystalline admixtures- was cured under wet burlap for seven days. Slabs 4 and 5 were cured using a water jet machine (Figure 2). In this case a water jet was applied four seven and fourteen days respectively. The water jet was applied three times per day, 10 minutes every time. 


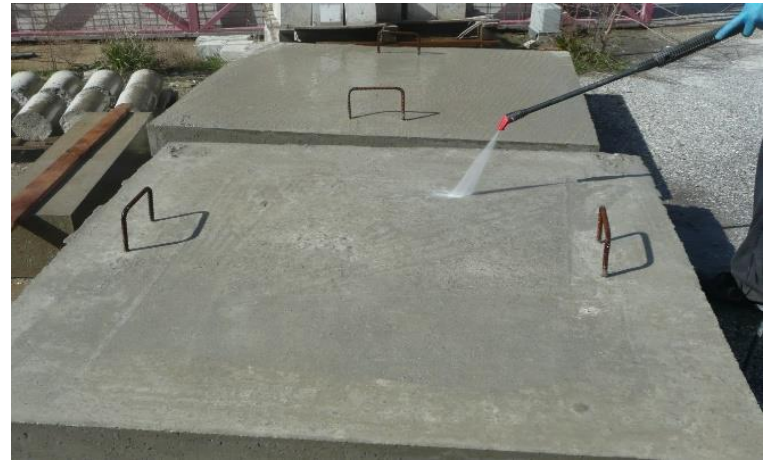

Fig. 2. Curing PRAH containing concrete slabs with water under pressure.

At the age of 28 days, core specimens were taken from all slab specimens. The core dimensions were $100 \times 100 \mathrm{~mm}$ and $60 \times 100 \mathrm{~mm}$ and were used for measuring the durability indicators of the elements.

\section{EXPERIMENTAL RESULTS DISCUSSION}

\subsection{Compressive strength.}

The compressive strength was measured for all concrete mixtures at the ages of 2 and 28 days. These values are shown in Table 3.

Table 3. Compressive strength of concrete mixtures (MPa)

\begin{tabular}{c|c|c|c|c|c|c|c|}
\hline \multicolumn{2}{c|}{$(\mathrm{MPa})$} & $\mathrm{C} 25 / 30$ & $\begin{array}{c}\text { C25/30- } \\
\text { PRAH }\end{array}$ & $\mathrm{C} 30 / 37$ & $\begin{array}{c}\text { C30/37- } \\
\text { PRAH }\end{array}$ & $\begin{array}{c}\text { REF- } \\
\text { C20/25 }\end{array}$ & $\begin{array}{c}\text { C20/25- } \\
\text { PRAH }\end{array}$ \\
\hline \multirow{2}{*}{$\begin{array}{c}2 \\
\text { days }\end{array}$} & $\mathrm{fc}_{2}$ & 26.9 & 21.2 & 31.4 & 31.6 & 20.5 & 20.8 \\
\cline { 2 - 8 } & $\mathrm{S}_{\mathrm{dev}}$ & 0.35 & 0.49 & 0.1 & 0.28 & 0.42 & 0.58 \\
\hline \multirow{2}{*}{28} & $\mathrm{fc}_{28}$ & 39.3 & 41.1 & 54.2 & 64.0 & 32.8 & 34.6 \\
\cline { 2 - 8 } days & $\mathrm{S}_{\text {dev }}$ & 0.3 & 0.1 & 0.7 & 0.5 & 0.51 & 0.28 \\
\hline
\end{tabular}

The values of the above table show the positive effect of crystalline admixture on the compressive strength of the mixtures. Both C30/37 mixtures showed the same compressive strength at the age of 2 days. However, the mixture prepared with addition of crystalline admixtures exhibited an increased strength of $9.8 \mathrm{MPa}(18.15 \%)$ relative to the reference mixture at the age of 28 days.

In the case of $\mathrm{C} 25 / 30$ mixtures, the 2-day strength of the alternative concrete is reduced by $5.65 \mathrm{MPa}(21.04 \%$ reduction) relative to the reference mixture, due to the $20 \%$ reduced cement content in this mixture. However, the gradual growth of the crystals resulted in an increase in the later strength of the alternative mixture, which at 28 days was measured at $41.10 \mathrm{MPa}$, i.e. $1.8 \mathrm{MPa}$ higher than the reference mixture (4.6 percent increase). In the case of $\mathrm{C} / 20 / 25$ concretes, both the 2 and 28 days compressive strengths were increased.

\subsection{Water absorption}

The water absorption of the concrete mixtures was estimated according to EN 13057 on $150 \mathrm{~mm}$ cube specimens. The specimens remained in the laboratory curing chamber until the age of 28 days. Then they were dried at $65{ }^{\circ} \mathrm{C}$ until their weight was stabilized. The specimens were then properly prepared (wrapped around the insulating tape to ensure absorption only from the bottom of the specimen) and after weighing they were placed in basins of clean water in such a way that the water covered 3-5 $\mathrm{mm}$ of height of the specimen.

Measurements of weight change of the specimens were performed at 10 minutes, 30 minutes, 60 minutes, 90 minutes, 120 minutes, 180 minutes, 240 minutes, 480 minutes and 24 hours. These weights were divided by the exposed surface of the specimen into the water to calculate the water absorbance in $\mathrm{gr} / \mathrm{m}^{2}$.

Table 4. Water absorption of concrete mixtures

\begin{tabular}{c|c|c|c|c}
\hline $\mathrm{kg} /(\mathrm{m} 2 . \mathrm{h} 0,5)$ & $\mathrm{C} 25 / 30$ & $\begin{array}{c}\mathrm{C} 25 / 30 \\
\text {-PRAH }\end{array}$ & $\mathrm{C} 30 / 37$ & $\begin{array}{c}\mathrm{C} 30 / 37- \\
\text { PRAH }\end{array}$ \\
\hline $\mathrm{S}_{\text {coefficient }}$ & 1.21 & 0.76 & 1.09 & 0.81 \\
\hline
\end{tabular}

The rate of water absorption was measured on slab specimens using the Karsten method also described by EN1323. This method estimates the surface water absorption under atmospheric pressure. Plastic tubes were moulded on the surface of the slabs and filled with water

The rate of water absorption is presented for all slab specimens in Fig. 3.

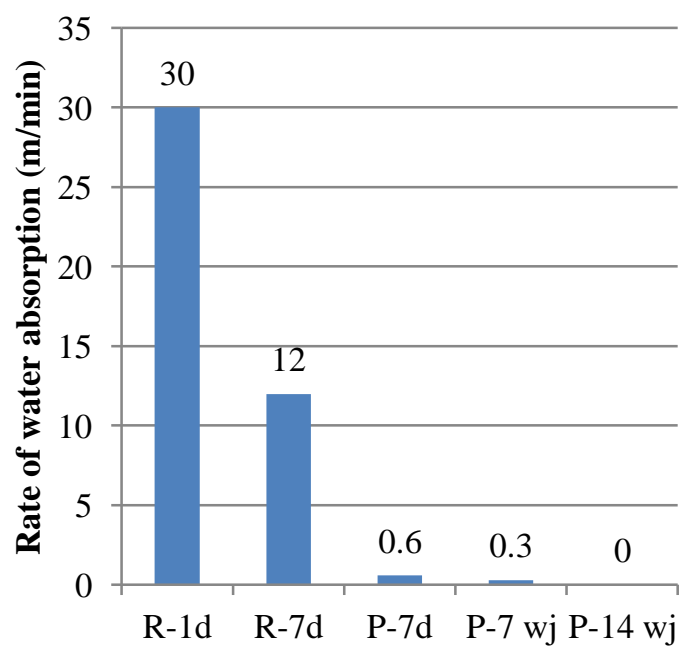

Fig. 3. Water absorption of concrete slabs cured with different curing scenarios.

It is well known that extension of the wet curing period facilitates the hydration of cement and therefore the more proper closure of porosity. Thus the extension of wet curing decreased the rate of water absorption of R$7 \mathrm{~d}$ concrete slab by $60 \%$. In the case of concrete slabs produced with crystalline admixture concrete, water absorption against atmospheric pressure was almost completely diminished. 


\subsection{Chloride penetration coefficient}

The Dnssm (non-steady-state migration) chloride diffusion coefficient values were measured according to NT Building 492 Standard [8] and are presented for all mixtures of the first phase in Table 5 .

Table 5. Dnssm chloride penetration coefficient $\left(\times 10^{-12} \mathrm{~m}^{2} / \mathrm{s}\right)$ of concrete mixtures.

\begin{tabular}{l|c|c|c|c|}
\hline $\mathrm{x} 10^{-12} \mathrm{~m}^{2} / \mathrm{s}$ & $\mathrm{C} 25 / 30$ & $\begin{array}{c}\mathrm{C} 25 / 30- \\
\text { PRAH }\end{array}$ & $\mathrm{C} 30 / 37$ & $\mathrm{C} 30 / 37-\mathrm{PRAH}$ \\
\hline Dnssm & 15.27 & 12.54 & 11.6 & 8.61 \\
\hline
\end{tabular}

The Dnssm chloride diffusion coefficient values were measured according to NT Building 492 on standard diameter concrete cores taken from the slab specimens and are presented for these mixtures in Table 6.

Table 6. Dnssm chloride penetration coefficient (x10-12m2/s) of concrete slabs cured with different curing scenarios.

\begin{tabular}{l|l|l|c|c|c|}
\hline $\mathrm{x} 10^{-12} \mathrm{~m}^{2} / \mathrm{s}$ & $\mathrm{R}-1 \mathrm{~d}$ & $\mathrm{R}-7 \mathrm{~d}$ & $\mathrm{P}-7 \mathrm{~d}$ & $\mathrm{P}-7 \mathrm{dwj}$ & $\mathrm{P}-14 \mathrm{dwj}$ \\
\hline Dnssm & 34.30 & 22.51 & 17.73 & 10.38 & 8.98 \\
\hline
\end{tabular}

The above coefficients were used to calculate the lifetime of reinforced concrete constructions cast with these mixtures. For this purpose the Life 365 program was used. The following assumptions were made: Exposure class XS1, time for the propagation of corrosion 10 years, $50 \mathrm{~mm}$ reinforcement cover. The total service life time is shown in the following diagram.

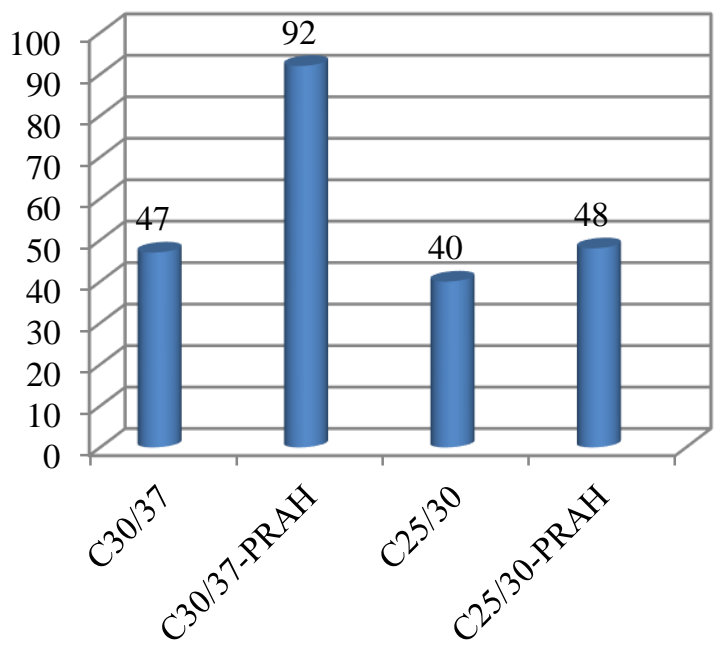

Service life (years)

Fig. 4. Service life of concrete mixtures.

The figure above shows the particularly positive effect of the crystalline admixtures on the service life of the concrete. The C30/37-PRAH mixture develops twice the lifetime of penetration of chlorides compared to the reference $\mathrm{C} 30 / 37$, while the $\mathrm{C} 25 / 30$-PRAH mixture has an increased lifetime of $20 \%$ over the reference $C 25 / 30$.
Crystal activation in both cases led to a drastic reduction in porosity, thus preventing penetration of chlorides into the mixtures.

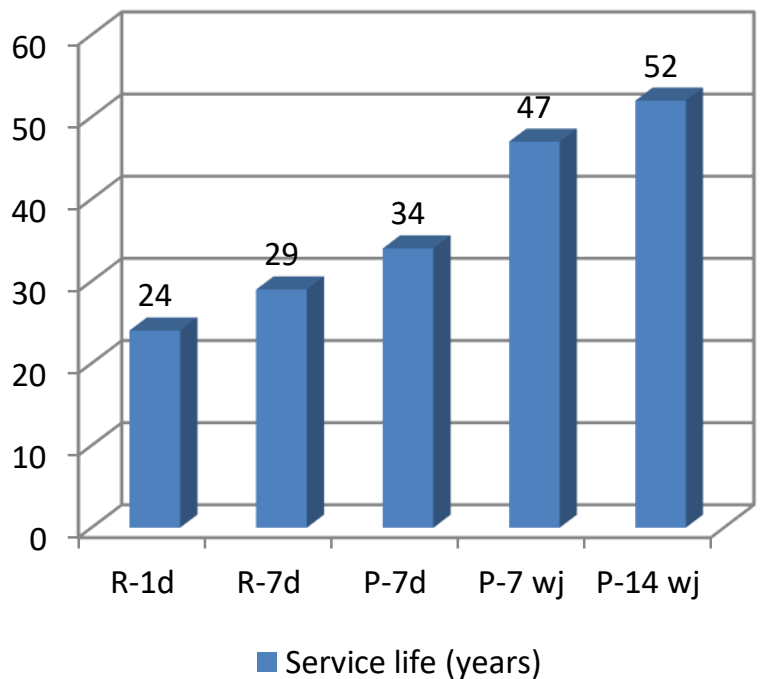

Fig. 5. Service life of concrete slabs cured with different curing scenarios.

The figure above shows the positive effect of the combination of using crystalline admixtures and extending the curing period on the service life of the concrete elements. Wet burlap curing increased the service life of the slab produced with crystalline admixture $(\mathrm{P}-7 \mathrm{~d})$ by $15 \%$ due to partial activation of the crystals. Since crystalline admixtures are hydrophilic at the beginning of their action, more water is needed for their activation. This additional water was provided by water jet. As indicated above, this method resulted in the formation of greater amounts of crystals that filled the pores and positively affected the resistance of concrete mixtures against ingress of chlorides. Thus the service life of P-7d wj and P-14d wj slabs was increased by $69 \%$ and $116 \%$ as compared with the reference slab (R-1d). What is more impressive is that even this poor concrete with the high w/c ratio fulfilled the requirements of Eurocodes for a design service life of 50 years when crystalline admixtures were added in the mixture and the concrete elements were properly cured.

\subsection{Carbonation depth}

The carbonation depth was measured according to the procedure described in EN 14630 Standard [9]. The specimens remained for 60 days in the Accelerating Carbonation Chamber. The carbonation depth of all mixtures of the first phase is shown in Table 7.

Table 7. Carbonation depth of concrete mixtures.

\begin{tabular}{|c|c|c|c|c|}
\hline & C25/30 & $\begin{array}{c}\text { C25/30- } \\
\text { PRAH }\end{array}$ & C30/37 & $\begin{array}{c}\text { C30/37- } \\
\text { PRAH }\end{array}$ \\
\hline $\begin{array}{c}\text { Carbonation } \\
\text { depth (mm) }\end{array}$ & 8,7 & 9,1 & 2,9 & 4,5 \\
\hline
\end{tabular}


The carbonation depth of the concrete slabs was evaluated on $60 \times 100 \mathrm{~mm}$ core specimens drilled from the slabs at the age of 28 days. After this age, core specimens were inserted in the accelerated carbonation chamber and remained there for 60 days. The carbonation depth, measured according to the EN 14630 Standard, is shown in Table 8.

Table 8. Carbonation depth of concrete slabs cured with different curing scenarios.

\begin{tabular}{|c|c|c|c|c|c|}
\hline & R-1d & R-7d & P-7d & $\begin{array}{c}\text { P-7d } \\
\text { wj }\end{array}$ & $\begin{array}{c}\text { P-14d } \\
\text { wj }\end{array}$ \\
\hline $\begin{array}{c}\text { Carbonation } \\
\text { depth (mm) }\end{array}$ & 19,8 & 18,8 & 16,5 & 14,2 & 12,5 \\
\hline
\end{tabular}

Based on the values of Table 8, it appears that the carbonation depth of the prepared mixtures is affected by the addition of the crystalline admixtures in a different way. In particular, the C25/30-PRAH mixture exhibits a slightly increased $5 \%$ carbonation depth relative to the reference mixture while the C30/37-PRAH mixture exhibits a carbonation depth increased by $55 \%$ relative to the $\mathrm{C} 30 / 37$ reference mixture. This may be due to the non-activation of the crystals; the specimens remained in a wet curing chamber for only three days, unlike the specimens used in the previous tests and which were maintained in the laboratory's wet curing chamber for 28 days. In addition, it should be noticed that the alternative C25/30-PRAH mixture was prepared with a $20 \%$ lower cement, while the C30/37-PRAH alternative was prepared using CEM II (B-M) $32.5 \mathrm{~N}$ cement more prone to carbonation due to its high pozzolan content.

The significance of curing slabs containing crystalline admixture with water under pressure for extended curing periods is clearly demonstrated in Table 7. Slabs produced with PRAH concrete (P-7d) showed a $5.3 \%$ lower carbonation depth as compared with slabs produced with the reference concrete $(\mathrm{R}-7 \mathrm{~d})$. In the case of PRAH concrete slabs cured under water pressure, the carbonation depth was decreased by $21.3 \%$ (P-7dwj) and $31.91 \%$ (P-a4dwj) respectively.

Long-term outdoor exposure experiments are underway in the Building Materials Laboratory in Xanthi in order to calculate the carbonation coefficient $\mathrm{k}$ and to assess more accurately the service life against carbonation of reinforced concrete structures exposed to environmental class XC4.

\section{Conclusions}

The crystalline PRAH additives used in the present study appear to be an effective way of sealing the porosity of the concrete prepared therewith. The presence of moisture is a catalytic factor for the activation of crystals which thus clog the pores of the cement and prevent the penetration of harmful fluids and gases. The alternative mixtures with crystalline PRAH additives that have been tested in the present study showed increased compressive strength, lower water absorption coefficient, and significantly lower permeability to chlorides than reference mixtures, thus enhancing the lifetime against seawater originated chlorides of reinforced concrete structures. These mixtures also exhibited a higher carbonation depth, due to the use of a different dosage and type of cement as well as to the low water curing period, which did not help to activate the crystals.

It was also found that curing concrete specimens with water under pressure is essential for the formation of crystals and the increase of durability of concrete elements.

Crystal admixtures and chemical additives used in the above experiments were provided by Penetron Hellas SA and NORDIA SA. Their support to the research work of the Building Materials Laboratory is greatly acknowledged.

\section{References}

1. EN 206-13, Concrete - Specification, performance, production and compliance, CEN, (2016)

2. P. Perkins, Repair, Protection and Waterproofing of Concrete Structures, Elsevier Applied Science Publishers, (1986), pp. 301

3. ACI Committee 212, Report on Chemical Admixtures for Concrete (ACI 212.3R-16), American Concrete Institute, Farmington Hills, MI, (2016), pp. 43-48

4. R.L. Munn, G. Kao, and Z.T. Chang, Durability Performance of Australian Commercial Concrete Modiied with Permeability Reducing Admixture, The 22nd Biennial of the Concrete Institute of Australia, Melbourne, Australia, (2005)

5. N. De Belie, M. Soutsos, E. Gruyaert, Properties of Fresh and Hardened Concrete Containing Supplementary Cementitious Materials, State-of-theArt Report of the RILEM Technical Committee 238$S C M$, Working Group 4, Springer Publishing, (2018), ISBN 978-3-319-70605-4

6. S.K. Roy, and D.O. Northwood, Admixtures to Reduce the Permeability of Concrete, Durability of Concrete: Proceedings of the Fourth CANMET/ACI Inter-national Conference, SP-170, V. M. Malhotra, ed., American Concrete Institute, Farmington Hills, MI, (1999), pp. 267-284

7. K.K. Sideris, C. Tassos, A. Chatzopoulos, P. Manita, Influence of PRAH crystalline admixtures on the durability of concrete. Proceedings of the 18th Greek Concrete Conference, (2018), pp. 83

8. NT-Build 492, Chloride migration coefficient from non-steady-state migration experiments, Nordtest methods, (1999)

9. EN 14630. Products and systems for the protection and repair of concrete structures - Test methods Determination of carbonation depth in hardened concrete by the phenolphthalein method, CEN, (2006) 